\title{
Radiosonde Temperature Measurements in Strong Inversions: Correction for Thermal Lag Based on an Experiment at the South Pole
}

\author{
Ashwin Mahesh, Von P. Walden, and Stephen G. Warren \\ Geophysics Program and Department of Atmospheric Sciences, University of Washington, Seattle, Washington
}

(Manuscript received 29 February 1996, in final form 5 July 1996)

\begin{abstract}
Very steep shallow temperature inversions occur during most of the year in the near-surface layer on the Antarctic Plateau. A radiosonde carried by a balloon rising at a few meters per second does not measure such inversions accurately because the response time of the thermistor is several seconds. To quantify this error, the authors flew a radiosonde on a tethered kite on several occasions in winter at South Pole Station immediately prior to the routine launch of the same sonde on a weather balloon. In all cases, the equilibrated temperatures measured by the tethered sonde at a given pressure level were higher than those from the balloon-borne sonde throughout most of the inversion layer. Assuming that the tethered sonde data represent the true atmospheric temperature profile, a procedure can be developed to correct the temperature data from routine radiosonde soundings for the finite response time of the thermistor. The authors devise an accurate deconvolution method to retrieve the true atmospheric temperature profile from the radiosonde data when the thermistor response time is known. However, a simple technique of shifting the profile a few seconds back in time gives results that are nearly equivalent to the deconvolution. Additional temperature errors result at the South Pole because the radiosonde is launched immediately after being brought out of a warm room, making it necessary to further adjust data from the lowest few tens of meters. It is found that the temperature errors cause a $0.3 \mathrm{~W} \mathrm{~m}^{-2}$ error in the computed downward longwave radiation flux in winter at the South Pole, most of which is in spectral regions dominated by emission from water vapor and carbon dioxide. This is similar to the $0.5 \mathrm{~W} \mathrm{~m}^{-2}$ change induced by the increase in carbon dioxide concentration from preindustrial to present values. The thermal lag is shown to be significant also for winter profiles in Alaska. A correction for thermal lag is recommended for all situations where radiosondes are used to measure steep temperature gradients in the boundary layer: in polar regions throughout the year, at midlatitude continental stations in winter, and at the tops of subtropical marine stratocumulus clouds.
\end{abstract}

\section{Introduction}

Temperatures reported by radiosondes are subject to several sources of error (Luers and Eskridge 1995), one of which is the thermal lag of the thermistor (Badgley 1957; Jensen 1958; Elliott and Gaffen 1991). The thermal lag has been of particular concern for measurement of temperature in the stratosphere, where the thermistor responds very slowly because of the low density of air. In the troposphere its response time is shorter, typically several seconds, and thermistors on the radiosondes used at U.S. weather stations have been unchanged since 1949 (Elliott and Gaffen 1991, Table 1; Jenne and McKee 1985, p. 1198). However, even in the troposphere the thermal lag can cause significant errors in reported temperature in situations where the sonde rises rapidly through a region where the vertical gradient of

Corresponding author address: Stephen G. Warren, Department of Atmospheric Sciences, Box 351640, University of Washington, Seattle, WA 98195-1640.

E-mail: sgw@atmos.washington.edu temperature is large (Huovila and Tuominen 1989). Weather balloons carrying radiosondes typically rise at a rate of 3-5 $\mathrm{m} \mathrm{s}^{-1}$ in the lower atmosphere. If the ascent rate of the balloon is constant, the thermistor's lag in time corresponds to a lag in height, so that at a given altitude, the thermistor reports a temperature more appropriate to some lower height that it passed through a few seconds earlier. Quantification and correction of this lag error are the primary topics of this paper. We focus on radiosonde temperature profiles taken at South Pole Station, since steep surface-based temperature inversions occur there most of the year.

A further, related problem is that the radiosonde and its balloon are sometimes prepared in a heated or airconditioned room and then released before the sonde equilibrates to the outside air temperature (Schwartz and Doswell 1991). This causes the temperatures reported in the lowest few tens of meters to be higher or lower than those of the ambient air. The height to which this memory of the balloon inflation room's temperature is significant depends on the actual radiosonde response time, the balloon ascent rate, and how soon the sonde 


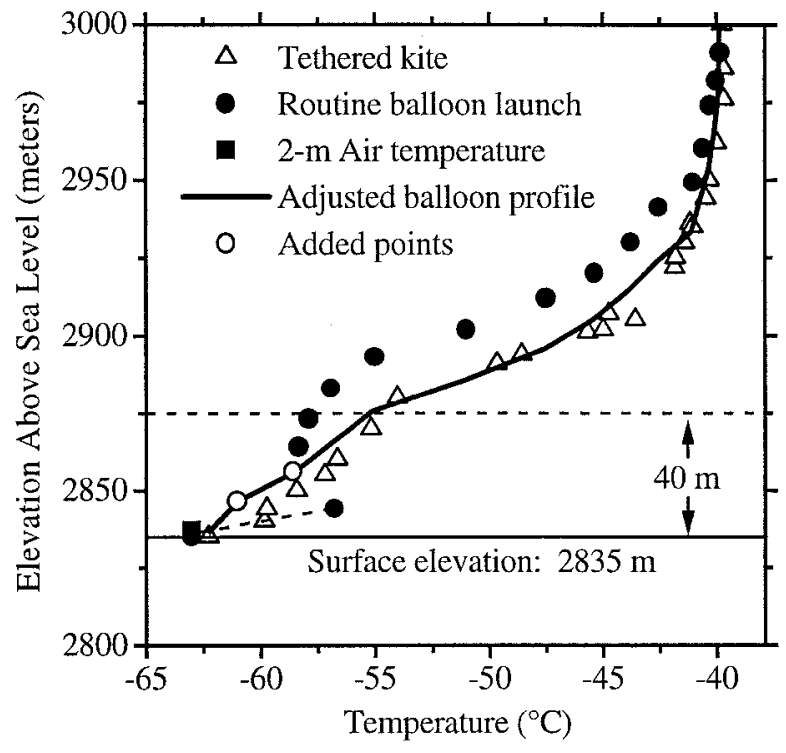

FIG. 1. Atmospheric temperature profiles above South Pole Station for 0000 UTC 28 August 1992. The filled circles are data points from the routine radiosonde launch of the South Pole Weather Office (SPWO); the open triangles are data reported by the same radiosonde on a tethered kite prior to the launch. The first point in the reported temperatures (the solid square) is not measured by the radiosonde, but is instead added to the radiosonde report from an SPWO thermometer at $2 \mathrm{~m}$. The adjusted balloon profile is shown as a solid line. Radiosonde data below the dashed horizontal line at $2875 \mathrm{~m}$ are ignored in the adjustment procedure as discussed in the text; the balloon reached this height after $9 \mathrm{~s}$. Data from other near-surface thermometers at South Pole Station that are inserted into the adjusted profile are shown as open circles.

is launched after leaving the inflation room. At the South Pole, the balloon and sonde are prepared in a heated balloon inflation tower (BIT).

Radiosondes report both temperature and humidity, but in this paper we consider only the temperature measurements. Radiosonde humidity sensors are typically calibrated only to $-40^{\circ} \mathrm{C}$, and we found that the sensors used at the South Pole were insensitive at temperatures below $-50^{\circ} \mathrm{C}$ (Walden and Warren 1996, manuscript submitted to J. Geophys. Res., Fig. 9). During our experiments, surface temperatures were in the range $-62^{\circ}$ to $-70^{\circ} \mathrm{C}$, so the humidity data are not usable. Lag errors for humidity have been discussed by Brousaides and Morrissey (1974).

\section{Data}

The radiosondes used at the South Pole are supplied by Atmospheric Instrumentation Research (AIR), whereas most U.S. weather stations use radiosondes supplied by VIZ Manufacturing Co. However, their thermistors are identical. AIR actually obtains sondes from VIZ but replaces the pressure sensor and data transmitter (J. Roby, AIR, 1996, personal communication). Both sondes have capacitive pressure sensors, which have response times of tens of milliseconds (Maz-
TABle 1. Differences among the 2-m thermometers at South Pole Station. Here $T_{h}$ are 2-m temperatures recorded hourly by the SPWO; $T_{r}$ are the 2-m temperatures inserted into radiosonde reports, also collected by the SPWO using a different thermometer on the same observation tower. Both thermometers are aspirated. Comparisons are made by interpolating the hourly values of $T_{h}$ to the time of launch. Here $T_{a}$ are 2-m temperatures from an unaspirated thermometer mounted on the walk-up tower and maintained by NOAA. Monthly average values of the temperature and temperature differences, indicated by the overbar, are given here for the year 1992 .

\begin{tabular}{lccc}
\hline \hline Month (1992) & $\overline{T_{h}}\left({ }^{\circ} \mathrm{C}\right)$ & $\overline{T_{r}-T_{h}}(\mathrm{~K})$ & $\overline{T_{a}-T_{h}}(\mathrm{~K})$ \\
\hline January & -29.3 & -0.1 & 1.3 \\
February & -43.1 & 0.0 & 1.4 \\
March & -56.7 & -0.1 & 1.0 \\
April & -53.3 & -0.1 & 0.5 \\
May & -59.0 & -0.3 & 0.6 \\
June & -55.5 & -0.4 & 0.6 \\
July & -60.1 & -0.4 & 0.5 \\
August & -60.7 & -0.5 & 0.6 \\
September & -57.9 & -0.3 & 0.5 \\
October & -47.1 & -0.1 & 0.5 \\
November & -39.4 & 0.0 & 1.0 \\
December & -30.2 & -0.1 & 1.7 \\
\hline
\end{tabular}

zarella 1985); this is much less than the few-second response time of the thermistor.

To quantify the temperature errors, we flew a radiosonde on a tethered parafoil kite at South Pole Station on nine occasions in August and September of 1992, immediately prior to the routine launch of the very same radiosonde by the South Pole Weather Office (SPWO). The kite was stopped at different altitudes, allowing the thermistor to equilibrate to its surrounding temperature. The kite was then reeled in, and the sonde was launched on a balloon. Five of these experiments were successful in obtaining kite profiles that extended through the inversion layer; at other times, the wind was too weak to lift the kite sufficiently. Figure 1 shows an example of the difference between a balloon profile and the corresponding kite profile.

The solid square is the 2-m air temperature measured by an SPWO thermometer upwind of the station. This temperature is an instantaneous reading made by the observer while initializing the AIR software and is routinely inserted as the first temperature in the sounding. The dashed line between the 2-m temperature and the first reported sonde temperature signifies that they are part of the same sounding. The solid circles below the horizontal dashed line (at $40 \mathrm{~m}$ above the surface) are affected by memory of the warm BIT (see section 3 ). The figure shows that the temperatures reported by the balloon-borne sonde differ by several degrees from those reported by the tethered sonde within the inversion layer. The two profiles begin to agree as the air temperature changes more slowly near the top of the inversion, $150 \mathrm{~m}$ above the surface.

A further complication is the lack of agreement among three 2-m temperature sensors used at South Pole Station. The South Pole Weather Office, maintained by 
Antarctic Support Associates under contract from the National Science Foundation, operates two of these instruments. These are platinum-resistance thermometers made by Rosemount Inc. of Chatsworth, California; both are aspirated. They are located a few centimeters apart on the same observation tower. One is used for recording routine hourly observations of the 2-m air temperature $\left(T_{h}\right)$, but it is the other whose temperatures $\left(T_{r}\right)$ are inserted into the radiosonde profile. The third sensor $\left(T_{a}\right)$, a platinum-resistance thermometer made by Logan Enterprises of West Liberty, Ohio, is located on a different meteorological tower less than $100 \mathrm{~m}$ away (Warren et al. 1993) and is operated by personnel of the Climate Monitoring and Diagnostics Laboratory (CMDL) of the National Oceanic and Atmospheric Administration (NOAA). This tower also has a temperature sensor at $21 \mathrm{~m}$, as discussed below. Table 1 shows that $T_{r}$ differs from $T_{h}$ mainly in the wintertime, possibly due to different calibrations at low temperatures; $T_{a}$ and $T_{h}$ differ in all months, but by a larger amount during sunlit times, probably indicating a bias in one of the sensors as well as the influence of sunlight on the CMDL sensor, which was not aspirated in 1992. It has since been replaced with an aspirated thermometer, as has the 21-m thermometer.

\section{Method}

Since the thermistor has a nonzero response time, the reported temperature from the balloon-borne sonde, $T_{\text {bal }}$, can be approximated as a linear combination of the air temperatures $T_{\text {air }}$ experienced at earlier times. The contribution of each $T_{\text {air }}$ falls off with time in accordance with the response time of the thermistor. In the following derivation, we assume that the data are reported by the radiosonde at regular time intervals of spacing $\delta t$. At the South Pole, $\delta t$ is $2 \mathrm{~s}$. At any time $t_{j}$, the temperature reported by the balloon-borne radiosonde, $T_{\text {bal }}\left(t_{j}\right)$, can be related to the actual temperatures in the atmosphere it has passed through: $T_{\text {air }}\left(t_{1}\right), T_{\text {air }}\left(t_{2}\right), T_{\text {air }}\left(t_{3}\right), \ldots, T_{\text {air }}\left(t_{j}\right)$, where $t_{j}=t_{j-1}+\delta t$ and $t_{1}$ is the time of the first report from the sonde. Using the standard notation of inversion theory (Twomey 1977), we set $g_{j}=T_{\text {bal }}\left(t_{j}\right)$ and $f_{j}=$ $T_{\text {air }}\left(t_{j}\right)$, and obtain $g_{j}$ as a weighted average of the $f_{k}$ at preceding times, $k \leq j$ :

$$
g_{j}=\frac{\sum_{k=1}^{j} W_{j k} f_{k}}{\sum_{k=1}^{j} W_{j k}},
$$

where the weights are

$$
W_{j k}=\exp \left[-(j-k) \frac{\delta t}{\tau}\right]
$$

and $\tau$ is the $e$-folding response time of the thermistor.
Equation (1) can be conveniently rewritten as a matrix equation:

$$
g_{j}=\sum_{k=1}^{j} K_{j k} f_{k}, \quad \text { or } \quad \mathbf{g}=\mathbf{K} \mathbf{f},
$$

where $\mathbf{g}$ and $\mathbf{f}$ are column vectors and the kernel $\mathbf{K}$ is a lower-triangular matrix whose $j k$ th element is given by

$$
K_{j k}=\frac{W_{j k}}{\sum_{k=1}^{j} W_{j k}} .
$$

In practice, the computation can be made more efficient by zeroing the leading elements of each row because they are negligible and retaining only those $K_{j k}$ for which $j-k \leq 30$. The triangular matrix then becomes a banded matrix. For the first few reported temperatures $\left(g_{1}, g_{2}\right.$, ...), Eq. (1) offers a poor description because it does not contain the history of the sonde's environment prior to launch $(k \leq 0)$. We therefore require a time span of $2 \tau$ to elapse after launch before using (1); that is, we use the reported values $g_{j}$ only for $j \geq 2 \tau / \delta t$. In Fig. 1, this level is indicated by the horizontal dashed line. Fortunately, all weather stations have a fixed thermometer measuring temperature at about 2-m height, and this temperature is inserted into the beginning of the data stream to augment the sounding before it is distributed and archived. To complete the temperature profile, one can therefore interpolate between the lowest derived temperature and the 2-m temperature, using additional data if available. The thickness of this " $2 \tau$ " layer actually varied between 34 and $73 \mathrm{~m}$ in our five experiments because of variations in ascent rate and thermistor response time. However, in our analysis we used $40 \mathrm{~m}$ as the thickness in all five cases and found it to be adequate.

Knowing the ascent rate of the balloon, the vectors $\mathbf{f}$ and $\mathbf{g}$ can be expressed as functions of height instead of time, and an approximate atmospheric temperature profile $\mathbf{f}^{\prime}$ can be inferred from the measurements $\mathbf{g}$ by inverting (3) using the least squares solution

$$
\mathbf{f}^{\prime}=\left(\mathbf{K}^{\mathrm{T}} \mathbf{K}\right)^{-1} \mathbf{K}^{\mathrm{T}} \mathbf{g} .
$$

Equation (5) is an unstable inversion because of the presence of measurement errors in $\mathbf{g}$, so it must be constrained in some way. A constraint can easily be incorporated into the solution, as shown by Twomey (1977). A popular constraint is to require the derived profile $\mathbf{f}^{\prime}$ to be smooth minimizing its second derivative. However, for the problem of deconvoluting radiosonde temperatures, we found that the inversion process works better if instead the constraint is an a priori estimate of the solution vector (called $\mathbf{h}$ ), which is given a specified weight. Following Twomey (1977), a least squares solution for $\mathbf{f}^{\prime}$ is then obtained as

$$
\mathbf{f}^{\prime}=\left(\mathbf{K}^{\mathrm{T}} \mathbf{K}+\gamma \mathbf{l}\right)^{-1}\left(\mathbf{K}^{\mathrm{T}} \mathbf{g}+\gamma \mathbf{h}\right),
$$


TABLE 2. The response times $\tau_{\mathrm{J}}$ of the radiosondes used in the five kite experiments, as determined by the shift in time needed to minimize the difference between the adjusted balloon data and the kite data. The range of possible $\tau_{\mathrm{J}}$ values due to maximum temperature changes between the times of the kite and balloon flights is also given.

\begin{tabular}{cccc}
\hline \hline $\begin{array}{c}\text { Date } \\
(\text { 0000 UTC })\end{array}$ & $\begin{array}{c}\text { Ascent } \\
\text { rate } \\
\left(\mathrm{m} \mathrm{s}^{-1}\right)\end{array}$ & $\tau_{\mathrm{J}}(\mathrm{s})$ & $\begin{array}{c}\text { Range of } \\
\text { possible } \\
\tau_{\mathrm{J}}(\mathrm{s})\end{array}$ \\
\hline 28 August 1992 & 4.4 & 4 & $3-4$ \\
2 September 1992 & 2.7 & 9 & $7-9$ \\
3 September 1992 & 3.3 & 18 & $13-18$ \\
11 September 1992 & 2.6 & 13 & $9-13$ \\
18 September 1992 & 4.2 & 5 & $4-7$ \\
\hline
\end{tabular}

where $\gamma$ is a "Lagrangian multiplier" chosen such that the residual $\left|\mathbf{K f}^{\prime}-\mathbf{g}\right|$ is comparable to the estimated error in the measurements $\mathbf{g}$, and $\mathbf{I}$ is the identity matrix of size $\mathbf{K}^{\mathrm{T}} \mathbf{K}$. The multiplier $\gamma$ ranges between 0 and $\infty$; $\gamma=0$ results in no constraint [Eq. (5)], and $\gamma=\infty$ forces $\mathbf{f}^{\prime}=\mathbf{h}$.

\section{Results}

In an earlier attempt to correct radiosonde temperatures for thermal lag, Jensen (1958) recommended that the reported temperature at time $t$ should simply be assigned to the pressure measured at the earlier time $t-$ $\tau$. From our measured values of the true air temperature $T_{\text {air }}$ collected by the tethered sondes, we determine this "Jensen profile" by shifting the balloon profile downward assuming various values of $\tau$ until the shifted profile agrees as closely as possible with the kite temperatures. We find the optimum choice of $\tau$ by minimizing the root-mean-square (rms) difference between the shifted temperatures and the kite profile within the inversion layer, ignoring points in the near-surface " $2 \tau$ layer." The result is an estimate of the response time $\tau_{\mathrm{J}}$ (using the subscript $\mathbf{J}$ for Jensen). The response times we find are applicable to the South Polar near-surface layer; with decreasing pressure, the response time increases.

Table 2 shows the values of $\tau_{\mathrm{J}}$ we obtain for the five soundings, indicating a range of response times from 4 to $13 \mathrm{~s}$, with one outlier at $18 \mathrm{~s}$ to be discussed below. This variability may be partially due to manufacturing differences among radiosondes and perhaps also due to differences in ventilation at different ascent rates. However, the $\tau_{\mathrm{J}}$ may also be affected by nonideal conditions during our experiments. The values we obtain are based on the assumption that the temperature structure in the inversion layer did not change between the time of the tethered kite experiment and that of the routine weather balloon launch one hour later. To test the validity of that assumption, we used data recorded at 10-min intervals by the CMDL thermometers on the meteorological tower to determine temperature trends during our experiments. The temperatures at 2 and $21 \mathrm{~m}$ during the hour prior to the balloon launch differed from that at the time of launch by less than $1.3 \mathrm{~K}$. By shifting each

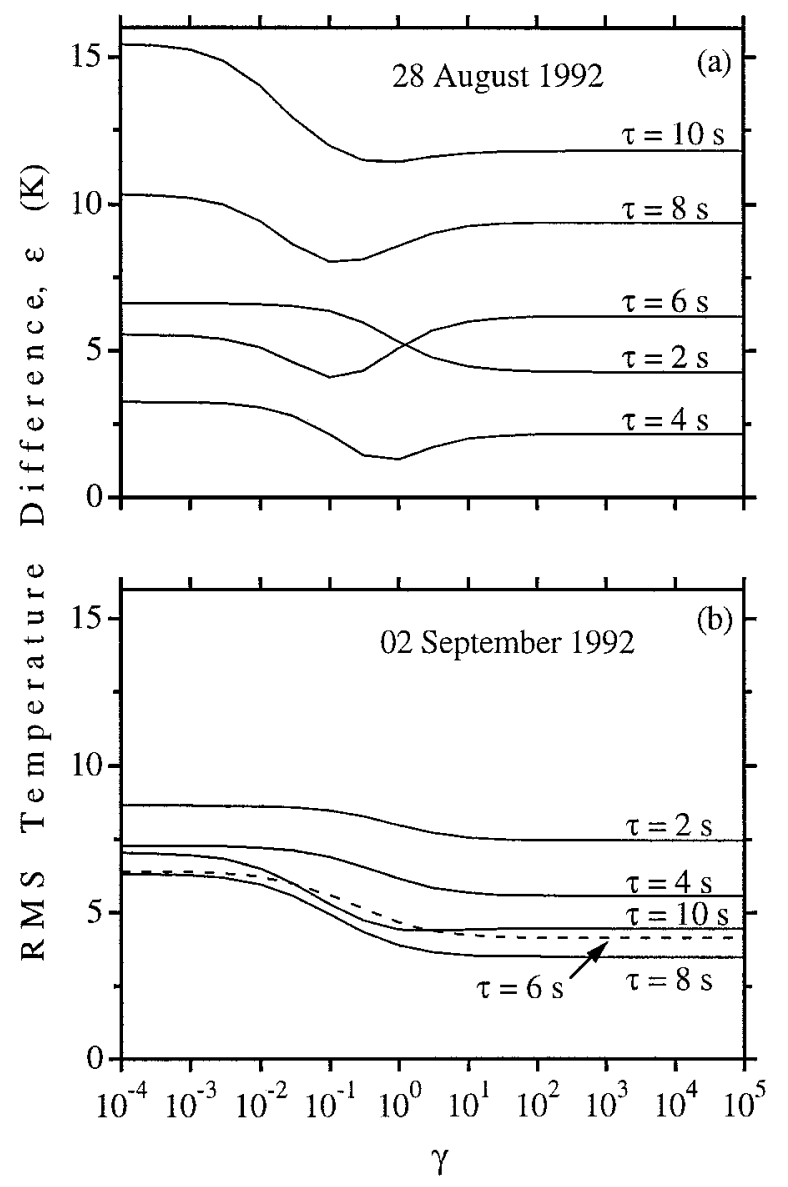

FIG. 2. The rms temperature difference $(\epsilon)$ between the deconvoluted balloon profiles and the tethered kite profiles data using various combinations of $\tau$ and $\gamma$. The difference is computed at altitudes from $40 \mathrm{~m}$ above the surface (or about $2 \tau$ ) to the top of the tethered kite profile. (a) On 28 August 1992, $\epsilon$ reached a minimum at $\gamma=1$ and $\tau=4 \mathrm{~s}$. In the other four cases, one of which is shown in (b), no minimum was obtained, indicating that the inversion procedure offered no improvement over the Jensen profile.

entire balloon profile by the maximum change during the previous hour, we recalculated the values of $\tau_{\mathrm{J}}$ for the five cases to see how this change in temperature might have affected our determination (Table 2). The derived response times for the five radiosondes still show significant differences, even allowing for this effect.

Now using the Jensen profile as our a priori estimate $\mathbf{h}$ in our deconvolution, we minimize the rms difference between $\mathbf{f}^{\prime}$ and $\mathbf{f}$ within the inversion layer by varying $\tau$ and $\gamma$. Figure 2 a shows that a minimum exists for the 28 August case at $\tau=4 \mathrm{~s}$ and $\gamma=1$. However, Fig. $2 \mathrm{~b}$ indicates that on 2 September the best fit to the tethered kite temperatures occurs at high values of $\gamma$, where $\mathbf{f}^{\prime} \approx \mathbf{h}$. This is also true of the other three cases. Therefore, we conclude that our deconvolution method is not a significant improvement upon Jensen's method, if our criterion is the ability of the adjusted profile to match the kite profile. 
The principal benefit we desire from the deconvolution is to bring the smooth balloon profile into agreement with the kite profile. Our main interest is to obtain accurate calculations of radiation spectra as illustrated below, where small (meter scale) deviations from the smoothed profile have little effect. Small-scale structure in the inversion layer that is not resolved by Jensen's method could possibly be resolved by the deconvolution procedure using a small value of $\gamma$, but we are unable to judge the accuracy of such small-scale structure because it usually does not persist long enough to be seen in both profiles taken one hour apart.

Having rejected the data from the first $40 \mathrm{~m}$, we assign values for the temperatures at these heights to supersede the Jensen profile. The first point in the radiosonde dataset is still useful, since it is recorded by the SPWO thermometer at $2 \mathrm{~m}$, which is equilibrated with its environment. Temperatures are also available at $21 \mathrm{~m}$ from CMDL and at $11 \mathrm{~m}$ from a thermistor attached to a pyrgeometer (Walden 1995). Figure 1 shows the adjusted profile (solid line) and the inserted points (open circles).

The 11- and 21-m temperatures in the adjusted profile in Fig. 1 are lower than those reported by the kite, for two main reasons. First, on 28 August, the temperature at $21 \mathrm{~m}$ decreased by about $1 \mathrm{~K}$ between the tethered kite experiment and the balloon launch. The remaining difference may be due to a "heat island" effect. The 11- and 21-m temperatures were measured upwind of the station, whereas the kite was flown just downwind. Although the station is small, in winter the difference between indoor and outdoor temperatures is typically $80 \mathrm{~K}$, so such an effect is plausible. The heat island effect is another reason why the procedure for the determination of $\tau_{\mathrm{J}}$ should not use data in the lowest part of the sounding.

Raw and corrected temperature profiles for all five days are compared to kite flights in Fig. 3. Having the tethered kite data for these five days allows us to determine how much the reported temperatures need to be shifted, thereby giving an estimate for the response time of the thermistor (Table 2). However, for routine soundings throughout the year, we do not have the benefit of the kite data, so we must assume an average response time. The 3 September profile in Fig. 3 appears to be an outlier. Its $\tau_{\mathrm{J}}$ was poorly determined, because the balloon profile on this day had only two data points in the lowest $145 \mathrm{~m}$. This may be partly responsible for the high value of $\tau_{\mathrm{J}}$ determined for this case. We therefore take the average response time of the thermistor to be the average of the other four cases, that is, $8 \mathrm{~s}$. The response time should be proportional to atmospheric density, so this value of $8 \mathrm{~s}$ at the South Pole, at a surface pressure of $700 \mathrm{mb}$, corresponds to $5.6 \mathrm{~s}$ at sea level, in agreement with the 5-6-s value stated by the manufacturer.

The error due to thermal lag may be greater on average than it is in the cases shown here, since the in- versions shown in Fig. 3, except for 28 August, were actually weaker than the monthly average inversion. This is because the kite experiments were successful only on days with sufficient wind to lift the kite. Winds tend to mix the boundary layer, weakening the inversion.

We examined the possibility that corrections for thermal lag had been instituted at times in the past, especially in the 1950 s when the lag of the thermistors first began to be understood. Early studies of radiosonde thermal lags focused on corrections to temperatures recorded in the stratosphere, where the lags produce large errors because of the low air density (Badgley 1957). Although a correction for thermal lag may have been applied routinely in the past at some Antarctic stations (B. Gardiner 1993, personal communication), such a correction was apparently never applied at South Pole Station, even in its first years of operation in the late 1950s (E. Flowers 1994, personal communication). The radiosonde thermistors now used at South Pole Station are made by VIZ Manufacturing Co., as are those used at most other U.S. weather stations. These radiosondes are normally assumed to have a response time $\tau$ of 56 s (M. Friedman, VIZ Manufacturing Co., 1994, personal communication), but our experiments suggest that $\tau$ is variable (Table 2). No correction for thermal lag is now made to radiosonde data from U.S. stations either in the process of recording the data or in being sent out to the Global Telecommunications System to be archived (D. Gaffen, F. Schmidlin, and R. Tanner 1994, personal communication). Some corrections for solar heating of thermistors were instituted for data between 400 and $10 \mathrm{mb}$, but that procedure was discontinued when the thermistors began to be coated with white paint in 1960 (Jenne and McKee 1985; Gaffen 1994).

\section{Application to non-Antarctic locations}

Adjustments to the reported temperatures may be important at other high-latitude weather stations as well, where strong near-surface temperature inversions are common in winter. Most data available from such stations are at coarser time resolution than the 2-s data we have for South Pole Station. Before May 1995, only data from mandatory and significant levels were routinely available; however, data from U.S.-controlled upper-air sites are now available at 6-s resolution from the National Climatic Data Center. Also, supplementary temperature data (such as the tower temperatures at the South Pole) are not normally available. In such cases, we can still use the principles of the method we have developed for the South Pole. As an example, we took the mandatory- and significant-level temperatures reported by the radiosondes at Fairbanks, Alaska, in 1989, and shifted them by a similar procedure. This is justified since, prior to March 1990, VIZ radiosondes were used at Fairbanks (Schwartz and Govett 1992). Because the weather station at Fairbanks is at an elevation of only $135 \mathrm{~m}$, we used a response time of $5.6 \mathrm{~s}$. 


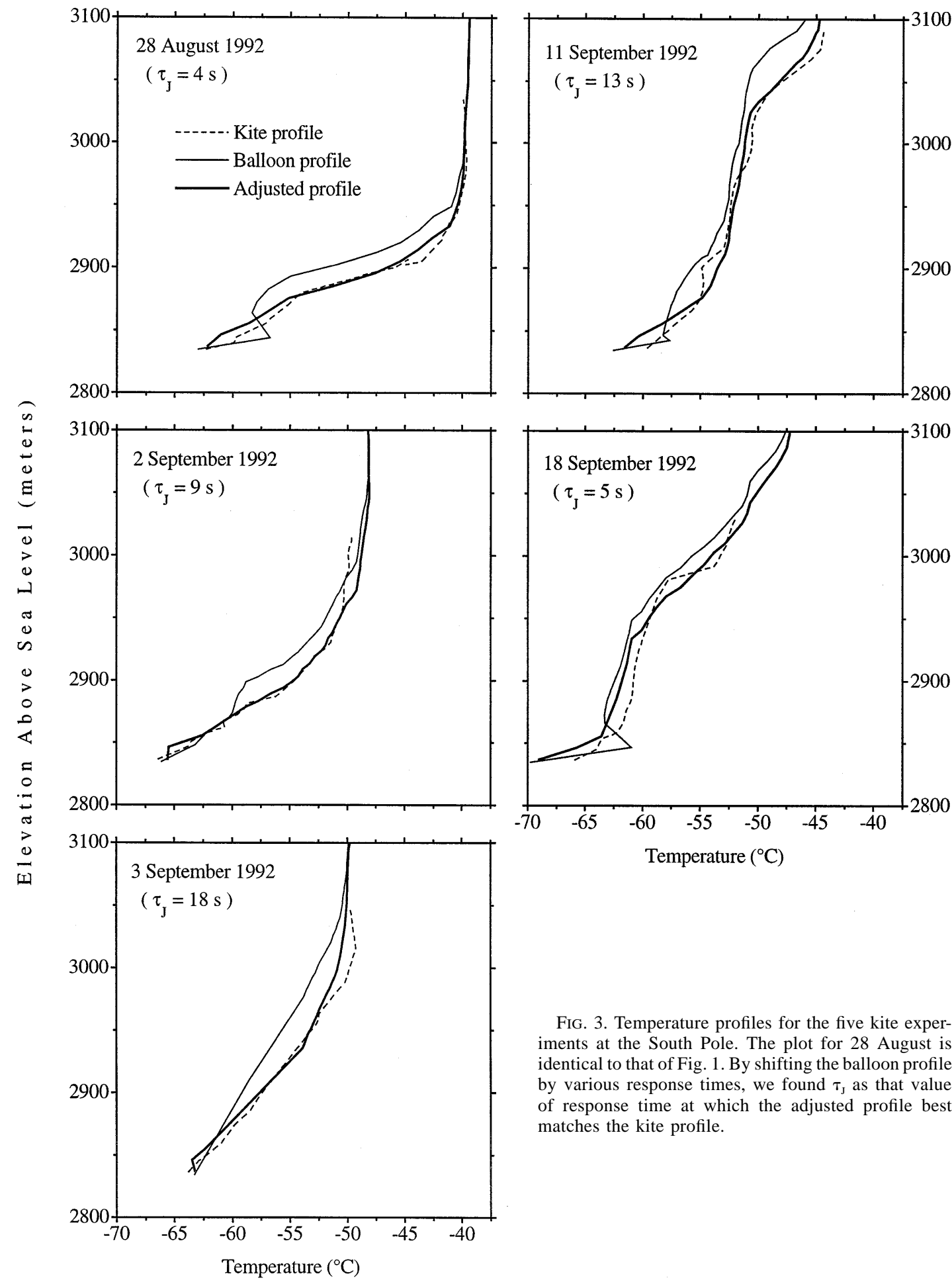

We ignored data within the $2 \tau$ layer, estimated to extend up to an elevation of $190 \mathrm{~m}$. We then specified a point at $190 \mathrm{~m}$ by interpolating between the heights at which data were available immediately below and above $190 \mathrm{~m}$. These data, from $190 \mathrm{~m}$ and upward, are then shifted by the estimated average response time of $5.6 \mathrm{~s}$ according to the Jensen procedure. We then linearly connect the point at $190 \mathrm{~m}$ to the $2-\mathrm{m}$ air temperature. Figure 4 shows the reported and adjusted profiles from data taken at Fairbanks. The effect of thermal lag on 


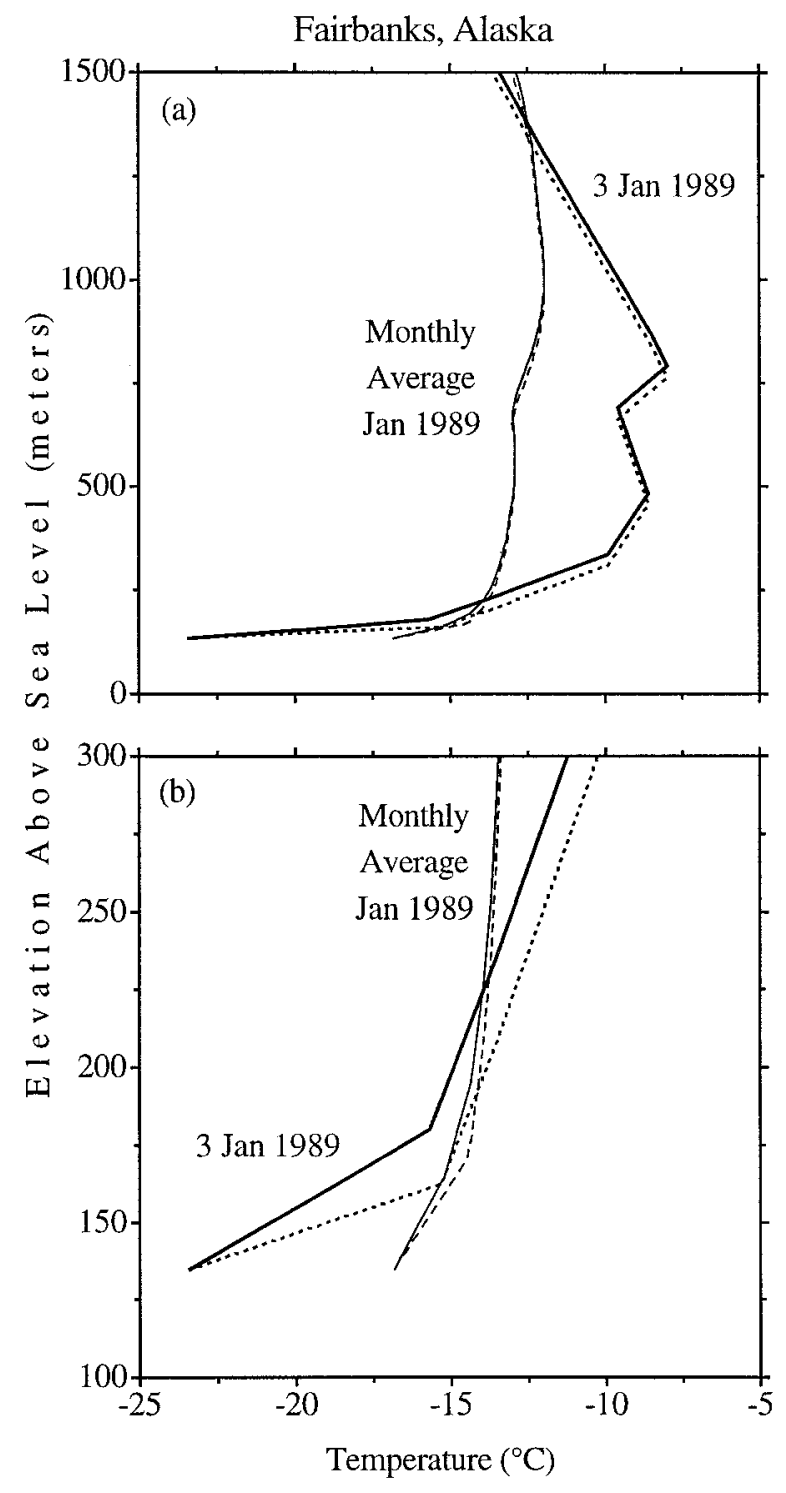

FIG. 4. Thermal lag corrections at Fairbanks $\left(65^{\circ} \mathrm{N}, 148^{\circ} \mathrm{W}\right)$. The solid lines are unadjusted profiles from the station; the dashed and dotted lines are the adjusted profiles. The lowest $160 \mathrm{~m}$ of the profiles are shown on an expanded scale in (b).

the accuracy of the temperatures is small in the monthly average profile. However, errors can be significant on individual days with steep inversions, as shown in the figure. These errors can affect the analysis of inversion heights (Huovila and Tuominen 1989; Skony et al. 1994; Walden et al. 1996).

\section{Implications for radiative transfer modeling}

The downward longwave radiation spectrum at the surface is affected by the near-surface atmospheric temperature structure. Temperature errors within the inversion layer at the South Pole may therefore cause significant errors in radiative transfer calculations. We in- vestigated this possibility using MODTRAN3, a radiative transfer model with moderate spectral resolution (Berk et al. 1989), in conjunction with temperature data from 2 September 1992. We show this case because its 9-s response time is closest to our estimate of the average response time. We computed the clear-sky downward infrared radiance at the surface from the adjusted profile and compared this spectrum to that calculated using the unadjusted profile. In these calculations, only the temperatures below the height of the inversion $(3.2$ $\mathrm{km}$ above sea level) were adjusted. The effects of possible lag errors above the near-surface layer were not investigated, because the lapse rate is sufficiently small through the free troposphere that the thermistor can respond adequately. Tropospheric water vapor concentrations were specified by saturating (with respect to ice) the near-surface layer up to the height of the inversion, and by setting the relative humidity above this layer, but below $7 \mathrm{~km}$, to $75 \%$ (Walden and Warren 1996, manuscript submitted to J. Geophys. Res.). Stratospheric values were fixed at $4 \mathrm{ppmv}$, consistent with measurements made by Rosen et al. (1991) at the South Pole in winter using sondes equipped with frost-point hygrometers. Since relative humidity is fixed in the model troposphere, the absolute humidity in the near-surface layer is higher in the adjusted profile than in the unadjusted one. The vertical profile of ozone was specified using CMDL ozonesonde data from 1992 (Bodhaine et al. 1993). Carbon dioxide concentrations at the South Pole come from Keeling and Whorf (1994), while other radiative gases such as methane and nitrous oxide are specified at the values of the subarctic winter model atmosphere (McClatchey et al. 1972).

Figure 5a shows the longwave spectrum for a viewing angle of $60^{\circ}$ between 0 and $2500 \mathrm{~cm}^{-1}$ (wavelength greater than $4 \mu \mathrm{m}$ ) using the adjusted temperature profile. Figure $5 \mathrm{~b}$ gives the error in radiance (bold line) caused by not adjusting the profile. Radiance differences occur mainly in spectral regions dominated by emission from water vapor and carbon dioxide. The differences are mostly negative because the reported temperature profile is colder than the true profile, and the reported humidity profile is drier than the true profile. The region of positive differences corresponds to the center of the carbon dioxide band, where the absorption length for photons is short, and occurs because the unadjusted profile is warmer than the adjusted profile in the first $20 \mathrm{~m}$ above the surface. Thus, the practice of launching radiosondes directly from the heated BIT at South Pole has a noticeable effect on radiative transfer calculations.

The downward longwave flux is determined by integrating the radiance over the hemispheric field of view (calculated at every $10^{\circ}$ of zenith angle) and over the entire longwave spectrum. The error in computed clearsky flux caused by using the unadjusted profile is about $-0.3 \mathrm{~W} \mathrm{~m}^{-2}$ out of a total of $58 \mathrm{~W} \mathrm{~m}^{-2}$. This error can be compared to the difference in flux using preindustrial instead of current concentrations of carbon dioxide, that 


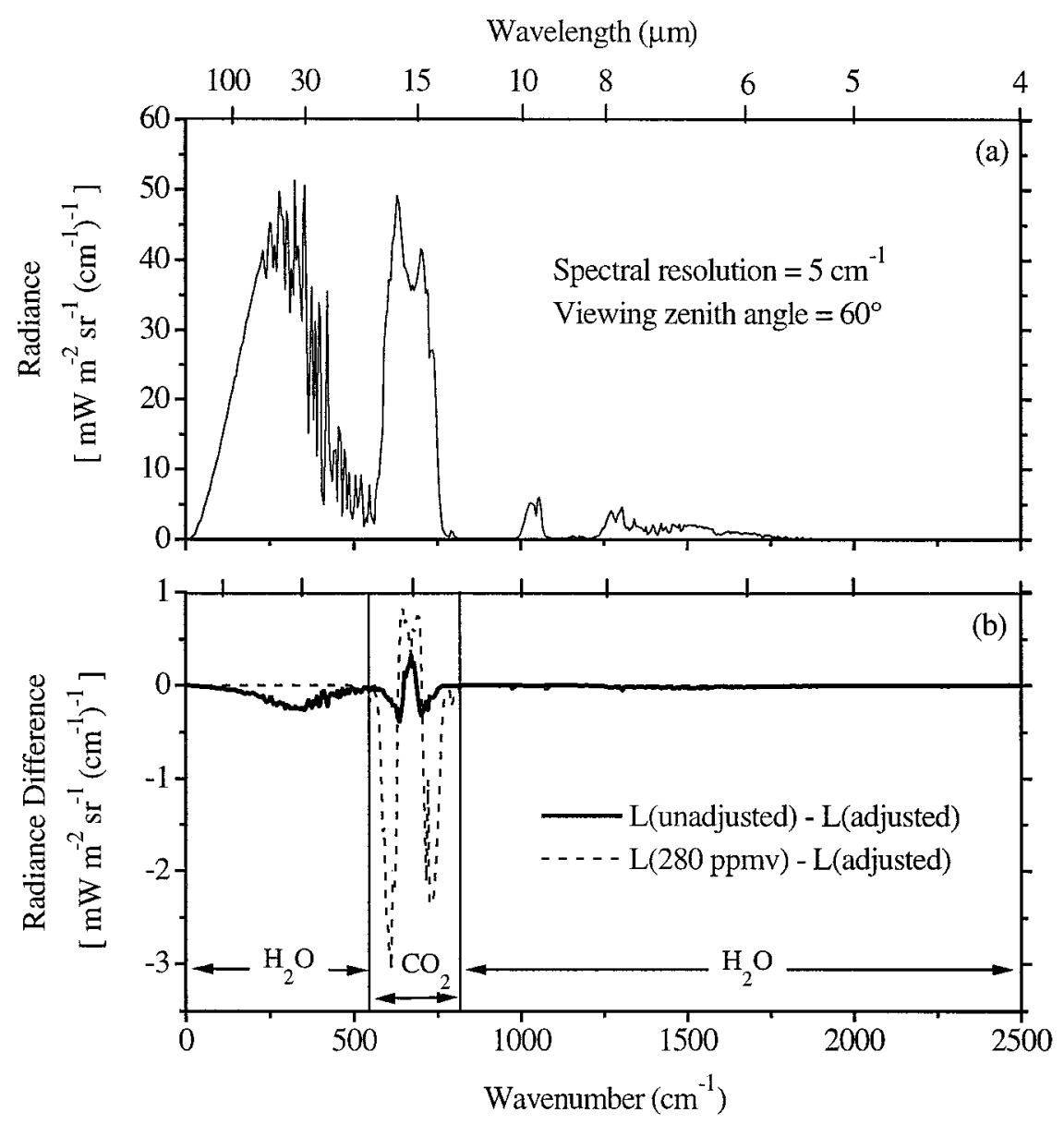

FIG. 5. (a) Spectral downward longwave radiance calculated by radiative transfer model MODTRAN3 using the adjusted temperature profile for 2 September 1992. (b) The effect on the computed downward longwave radiance caused by adjusting the reported temperatures at the South Pole. Here $L$ (adjusted) is the spectral radiance calculated using the adjusted temperature profile; $L$ (unadjusted) uses the temperature profile directly as reported by the balloon-borne radiosonde; $L(280 \mathrm{ppmv})$ is the spectral radiance using the adjusted profile, but with a carbon dioxide concentration of $280 \mathrm{ppmv} ; L$ (adjusted) and $L$ (unadjusted) use 360 ppmv.

is, 280 instead of 360 ppmv. The dashed line in Fig. 5b shows this difference; the corresponding flux difference is $-0.5 \mathrm{~W} \mathrm{~m}^{-2}$.

\section{Conclusions}

The slow response of thermistors used in radiosondes is useful to provide some smoothing in the measured temperature profile. However, in atmospheres with steep temperature gradients, the slow response causes the data to be biased. Correcting for the slow response is important not only at the South Pole but wherever rapid changes in temperature in the lower troposphere are recorded by balloon-borne radiosondes. Near-surface inversions are common in the Arctic throughout the year (Vowinckel and Orvig 1970) and at midlatitude continental locations in winter. The correction could also be significant at the tops of subtropical marine stratocumulus clouds, where, at a pressure level of 800-900 $\mathrm{mb}$, the reported temperature typically rises by $5-10 \mathrm{~K}$ over $50 \mathrm{~m}$ or less (Nicholls and Leighton 1986).

The error due to thermal lag can be corrected accurately if the response time of the radiosonde is known. However, different sondes, even those made by the same manufacturer, appear to have different response times. Why this variability exists is unclear. Possible explanations include inconsistent manufacturing and differences in ventilation produced by different ascent rates. A sophisticated deconvolution procedure turns out to be no more accurate than a simple shifting of the profile downward in height as proposed by Jensen in 1958. At the South Pole, temperature profiles should also be adjusted for errors caused by the balloon-launching procedure, namely, spurious warm temperatures reported immediately after the sonde has left the warm inflation tower. Such a correction may also be important in hot climates, if the sonde is prepared in an air-conditioned room that is significantly cooler than the outside ambient 
air (Schwartz and Doswell 1991). Allowing the radiosonde to equilibrate outdoors for $1 \mathrm{~min}$ before launch would eliminate such effects at both warm and cold stations and the need for supplementary data. The National Weather Service (1974) specifies that when the temperature at which the sonde is prepared for launch differs from the outside temperature by more than $30^{\circ} \mathrm{C}$, $10 \mathrm{~min}$ should be allowed for the sonde to equilibrate. Such a long wait might be necessary to allow the hygristor to register the true outside humidity, but the temperature sensor should equilibrate to the outside temperature within $1 \mathrm{~min}$.

Radiative transfer modeling indicates that the thermal lags produce a half-percent error in the downward longwave flux for clear sky in winter at the South Pole. This is comparable to that caused by the change in atmospheric concentration of carbon dioxide from preindustrial to current values.

Acknowledgments. We thank Prof. Takeshi Ohtake (University of Alaska) for the use of his kite and winch for the tethered kite experiments. The South Pole weather observers for 1992, Kitt Hughes and Bob Koney (National Weather Service, Kauai), provided considerable assistance with the tethered kite experiments and were essential to the success of the project. Dan Ireland, South Pole meteorologist for 1996, provided further information about procedures and instruments. We thank Dian Gaffen (NOAA), Maurice Friedman (VIZ Corp.), Ed Flowers (NOAA-ERL, retired), Brian Gardiner (British Antarctic Survey), Frank Schmidlin (NASA), and Roger Tanner (NOAA-NCDC) for information about radiosonde operational procedures. Sam Oltmans provided the ozone profiles. We thank Barry Schwartz and two anonymous reviewers for their comments. This research was supported by NSF Grants OPP-91-20380 and OPP94-21096.

\section{REFERENCES}

Badgley, F. I., 1957: Response of radiosonde thermistors. Rev. Sci. Instrum., 28, 1079-1084.

Berk, A., L. S. Bernstein, and D. C. Robertson, 1989: Modtran: A moderate resolution model for Lowtran 7. Rep. GL-TR-89-0122, 38 pp. [Available from Geophysics Laboratory, Hanscom Air Force Base, MA 01731-5000.]

Bodhaine, B., and Coauthors, 1993: Aerosol, radiation, ozone, and water vapor division. Climate Monitoring and Diagnostics Laboratory Summary Rep. 1992, 131 pp. [Available from NOAA, 325 Broadway, Boulder, CO 80303.]

Brousaides, F. J., and J. F. Morrissey, 1974: Residual temperatureinduced humidity errors in the National Weather Service radiosonde, final report. Rep. AFCRL-TR-74-0111, 40 pp. [Available from Meteorology Laboratory, Hanscom Air Force Base, MA 01731-5000.]
Elliott, W. P., and D. J. Gaffen, 1991: On the utility of radiosonde humidity archives for climate studies. Bull. Amer. Meteor. Soc., 72, 1507-1520.

Gaffen, D. J., 1994: Temporal inhomogeneities in radiosonde temperature records. J. Geophys. Res., 99, 3667-3676.

Huovila, S., and A. Tuominen, 1989: Effect of radiosonde lag errors on upper-air climatological data. WMO Instruments and Observing Methods Rep. 35, WMO/TD No. 303, 291-297 pp. [Available from World Meteor. Org., Publications Sales Unit, Case Postale 2300, CH-1211 Geneva 2, Switzerland.]

Jenne, R. L., and T. B. McKee, 1985: Data. Handbook of Applied Meteorology, D. D. Houghton, Ed., John Wiley and Sons, 11751281.

Jensen, A., 1958: Correction of radiosonde measurements for lag error. Geophysica, 6, 275-279.

Keeling, C. D., and T. P. Whorf, 1994: Atmospheric $\mathrm{CO}_{2}$ records from sites in the SIO air sampling network. Trends '93. A Compendium of Data on Global Change, T. A. Boden, D. P. Kaiser, R. J. Sepanski, and F. W. Stoss, Eds., Carbon Dioxide Information Analysis Center, 16-26.

Luers, J. K., and R. E. Eskridge, 1995: Temperature corrections for the VIZ and Vaisala radiosondes. J. Appl. Meteor., 34, 12411253.

Mazzarella, D. E., 1985: Measurements today. Handbook of Applied Meteorology, D. D. Houghton, Ed., John Wiley and Sons, 283328.

McClatchey, R. A., R. W. Fenn, J. E. A. Selby, F. E. Volz, and J. S. Garing, 1972: Optical properties of the atmosphere. Rep. AFCRL-72-0497, 108 pp. [Available from Geophysics Laboratory, Hanscom Air Force Base, Bedford, MA 01731.]

National Weather Service, 1974: Federal Meteorological Handbook No. 3, Radiosonde Observations. B2-21, 731 pp. [Available from Superintendent of Documents, U.S. Government Printing Office, Washington, DC 20402].

Nicholls, S., and J. Leighton, 1986: An observational study of the structure of stratiform cloud sheets: Part I. Structure. Quart. J. Roy. Meteor. Soc., 112, 431-460.

Rosen, J. M., N. T. Kjome, and S. J. Oltmans, 1991: Balloon borne observations of frost point and ozone in polar stratospheric clouds at the South Pole. Geophys. Res. Lett., 18, 171-174.

Schwartz, B. E., and C. A. Doswell III, 1991: North American rawinsonde observations: Problems, concerns, and a call to action. Bull. Amer. Meteor. Soc., 72, 1885-1896.

_ , and M. Govett, 1992: A hydrostatically consistent North American radiosonde data base at the Forecast Systems Laboratory, 1946-present. Tech. Memo. ERL-FSL-4, 81 pp. [Available from NOAA, 325 Broadway, Boulder, CO 80303.]

Skony, S. M., J. D. W. Kahl, and N. A. Zaitseva, 1994: Differences between radiosonde and dropsonde temperature profiles over the Arctic Ocean. J. Atmos. Oceanic Technol., 11, 1400-1408.

Twomey, S., 1977: Introduction to the Mathematics of Inversion in Remote Sensing and Indirect Measurements. Elsevier, 243 pp.

Vowinckel, E., and S. Orvig, 1970: The climate of the north polar basin. Climates of the Polar Regions, Vol. 14, World Survey of Climatology, S. Orvig, Ed., Elsevier, 129-252.

Walden, V. P., 1995: The downward longwave radiation spectrum over the Antarctic plateau. Ph.D. thesis, University of Washington, Seattle, WA, $267 \mathrm{pp}$.

—, A. Mahesh, and S. G. Warren, 1996: Comment on "Recent changes in the North American Arctic boundary layer in winter." J. Geophys. Res., 101, 7127-7134.

Warren, S. G., M. Starbuck, and C. Groeneveld, 1993: Relative elevations of meteorological facilities at South Pole Station. Antarct. J. United States, 28, 271-273. 